\title{
Material characterization of ancient Indian copper
}

\author{
A SRIVASTAVA and R BALASUBRAMANIAM* \\ Department of Materials and Metallurgical Engineering, Indian Institute of Technology, Kanpur 208 016, India
}

MS received 15 April 2003; revised 7 July 2003

\begin{abstract}
A chalcolithic (2350-1800 BC) copper chisel from Balathal has been characterized by X-ray diffraction, microstructural and electrochemical methods. The surface patina was composed of sulfates and oxysulfates in the outer layers while the inner layers were rich in copper oxides. The chisel exhibited smaller grain sizes near two of the surfaces while the structure in the interior was equiaxed. The deformed grains and inclusions near the surfaces and variation in the microhardness of the sample from different faces proved that the copper chisel was processed by cold deformation after initial casting of the square cross-section chisel. The electrochemical behaviour of chalcolithic $\mathrm{Cu}$ has been compared with that of a modern $\mathrm{Cu}$ sample by potentiodynamic polarization studies. The corrosion rate of chalcolithic $\mathrm{Cu}$ in aerated $3.5 \% \mathrm{NaCl}$ solution was only marginally higher than that of modern $\mathrm{Cu}$. The higher rate of corrosion has been attributed to the presence of second phase sulfide inclusions. The excellent condition of preservation of the 3800-year-old copper object, with no indications of stress corrosion cracking, suggests that pure copper or copper-based materials can be seriously considered as candidate canister materials for long-term underground storage of nuclear wastes in underground repositories.
\end{abstract}

Keywords. Ancient Indian copper; material characterization; electrochemical behaviour; rust analysis; corrosion rate.

\section{Introduction}

Recent excavations at Balathal in Udaipur District have revealed that it could be the oldest known village outside the domain of the Indus (Harappan) civilization (Misra et al 1995, 1997). Radiocarbon dating has provided firm dates between $2350 \mathrm{BC}$ and $1800 \mathrm{BC}$, thereby firmly placing it as a chalcolithic site (Misra et al 1995). Balathal is one among the several chalcolithic sites discovered in the Mewar region of south Rajasthan. The characteristic features of this culture are a variety of ceramics, beads of semi-precious stones and terracotta and animal figurines, copper technology, absence of stone blades and microliths, and an economy based on plant cultivation, animal husbandry, and limited hunting and fishing (Misra et al 1995). Excavations have revealed two cultural periods at Balathal-the Chalcolithic and Iron Ages. It appears that the settlers of Balathal came into contact with Harappan people of Gujarat after establishing their settlement. After an occupation lasting several centuries, the chalcolithic settlement at Balathal was abandoned by its inhabitants around $1800 \mathrm{BC}$ for reasons yet unknown. The same locality was reoccupied after a gap of more than 1200 years in the Iron Age by a new group of people, who used iron technology and possessed a different material culture. The reoccupation of the site suggests its importance

\footnotetext{
*Author for correspondence
}

as a strategic location and this has been confirmed by the discovery of a fortress-like structure (mud rampart) of the Iron Age (Misra et al 1995). The evidence for iron smelting and the manufacture of iron implements at the site further suggests its economic importance in the later Iron Age. The tools and weapons of the chalcolithic people of Balathal, however, were mainly made of copper. The Harappan influence was noted in the copper implements (barbed arrowheads, knives, chisel, chopper, nail) discovered at Balathal as they were similar to those found in association with Harappans. The mode of manufacture of these copper objects into desired shapes needs to be understood. The Balathal site is close to Ahar $(\sim 35 \mathrm{~km})$ from where the inhabitants could have obtained copper implements (Misra et al 1995, 1997). It has also been suggested that, as the site is close to copper ore deposits, the chalcolithic people could have exploited the same (Misra et al 1995). It is interesting to note that small stone blades and tools were completely absent at Balathal, but seen in all other chalcolithic sites. This clearly suggests that copper metal was plentifully available. In fact, a fireplace excavated inside a structural complex (see figure 8 of Misra et al 1995) has been suggested as being a furnace for smelting and working copper (Misra et al 1995).

Several copper tools and weapons were discovered in the chalcolithic site of Balathal. In the present investigation, a copper chisel (see figure 11 of Misra et al 1995 for a picture of the copper chisel) from Balathal was addressed by a detailed metallurgical investigation. Metal- 
lurgical investigations on ancient copper provide valuable insights on the long-term corrosion and degradation behaviour of copper. These valuable archaeological analogues assist in the selection and design of materials for long-term corrosion resistance, like those required for long-term underground storage of nuclear wastes. Copper is one of the natural materials of choice and investigations on archaeological copper would provide valuable inputs in material selection for canisters for long-term nuclear waste storage (Rosborg et al 2003). In this regard, the inputs from archaeologists would provide valuable insights in the materials selection problem.

\section{Experimental}

The copper chisel that was utilized in the present study was of square cross-section at one end, tapering down to a smaller flatter cross-section at another end. Its total length was $9 \mathrm{~cm}$ and cross-section at the square section was $0.86 \times 0.86 \mathrm{~cm}$. It was covered with an adherent surface patina, which appeared light green in colour. A small section was made at the square cross-section end using a diamond cutter. Samples of pure modern copper were also prepared for comparison purposes. Three samples were prepared from this section. The first sample was utilized for metallographic (optical and scanning electron microscopy) and microhardness measurements. The second sample was specifically maintained for careful X-ray diffraction (XRD) analysis. The third sample was mounted for electrochemical analysis. While cutting the samples, special care was taken to ensure that the surface scales (i.e. the corrosion products) were not disturbed, especially in the sample utilized for XRD analysis. The specimen for metallographic observations was hot mounted. Special care was taken during mounting to maintain the flatness of the sample and the mount. The cross-section of the chisel was the section observed on the microscope. The sample was ground and polished very carefully to avoid the reappearance of new scratches. The final polishing was performed with $1 \mu \mathrm{m}$ diamond paste. The specimen was etched in ferric chloride solution for revealing the microstructure. The microstructures were observed in an optical microscope and a JEOL 840A scanning electron microscope (SEM). The images from the optical microscope (Axiolab A, Zeiss, Germany) were grabbed in a digital camera (CE, Japan) and later used in an image analysis program (Image-Pro Plus $4 \cdot 1$, Media Cybernetics, USA). The volume fraction of the inclusions and the grain sizes were estimated. In order to measure the volume fraction, 30 fields of view (FOV) were captured (at a magnification of $\times 200$ ) and analysed. A $15 \times 11$ grid was imposed on each of the FOVs. The number of points falling in the feature of interest was counted manually and divided by the total number of grid points to provide the volume fraction. The linear intercept method was used for measuring the grain size. Thirty FOVs were captured and nine test lines were imposed on each of the FOVs using the software. The number of intersections between the test lines and the grain boundaries was counted. The total length of test lines divided by the total number of intersection points provided the grain size. Thirty FOVs helped to minimize statistical error.

The sample for electrochemical analysis was mounted in a cold setting epoxy, after soldering a conductive wire to it. Electrochemical polarization experiments were conducted utilizing a potentiostat (263A Perkin Elmer, USA). Polarization studies were carried out in $3.5 \mathrm{wt} \% \mathrm{NaCl}$ solution. The samples were polished to $4 / 0$ grade emery paper finish and the surfaces were cleaned using distilled water and acetone before the start of each experiment. A round-bottom polarization cell, with graphite counter electrodes and saturated calomel electrode (SCE) $(+241 \mathrm{mV}$ vs standard hydrogen electrode) reference electrode, was used in the electrochemical study. Potentiodynamic polarization experiments were conducted after stabilization of free corrosion potentials. Both chalcolithic $\mathrm{Cu}$ and modern $\mathrm{Cu}$ samples were tested. Corrosion rates were determined by the Tafel extrapolation and linear polarization methods. A scan rate of $1 \mathrm{mV} / \mathrm{s}$ was used for potentiodynamic polarization experiments and $0.166 \mathrm{mV} / \mathrm{s}$ for Tafel extrapolation, as per ASTM standards (ASTM 1987). In the case of Tafel extrapolation experiments, the potential was scanned from $-250 \mathrm{mV}$ to $+250 \mathrm{mV}$ with respect to the free corrosion potential (FCP), while in the case of linear polarization experiment, it was scanned from $-50 \mathrm{mV}$ to $+50 \mathrm{mV}$ with respect to FCP.

The microhardness variation, as a function of distance from the surface, was obtained from the four surfaces of the cross-section. The microhardness experiments were performed in a Carl Zeiss Jena 160 microhardness tester using a $60 \mathrm{~g}$ load. The hardness was measured across a line perpendicular to the surface, from the edge progressing towards the middle of the specimen, at systematic intervals. Six profiles were recorded from each of the four specimen surfaces and the average estimated for each data point.

The X-ray diffraction (XRD) experiments were conducted in a Rich-Seifert X-ray Diffractometer, taking special care to maintain the same conditions for all the experiments (constant current of $20 \mathrm{~mA}$ and voltage of the $\mathrm{X}$-ray tube, $30 \mathrm{kV}$ ). The wavelength of the radiation used was $\mathrm{CuK}_{\alpha}(1.54184 \AA)$. The XRD patterns were analysed by using DIFFRAC ${ }^{\text {plus }}$ Software (Bruker Advanced X-ray Solutions) and JCPDF database (JCPDF 2001). XRD patterns were first obtained from all the surfaces, and later, were again determined after slightly polishing off the surface layers using fine emery paper. It was not easy to identify the peaks due to high amount of noise and texturing and in this regard the DIFFRAC ${ }^{\text {plus }}$ software was very useful in removing some noise and texturing effects. 


\section{Results and discussion}

The results of the present study are discussed in the following sections.

\subsection{X-ray diffraction analysis}

The XRD patterns obtained from all the four faces of the as-received material were similar, barring some very minor variations. This indicated that the environment, to which the copper chisel was exposed to, was uniform, and resulted in a relatively uniform chemical nature of the four exposed faces of the copper chisel. A typical diffraction pattern obtained from the surface is shown in figure 1a. The peaks were compared with that of the common corrosion products of $\mathrm{Cu}$ (JCPDF 2001). Apart from peaks due to the substrate $\mathrm{Cu}$, all the other peaks could be indexed unambiguously to specific corrosion products. It was firmly concluded that the major corrosion products on the surface of the sample were hydrated copper sulfates and oxysulfates (figure 1a). The specific phases identified were: $\mathrm{Cu}_{4}\left(\mathrm{SO}_{4}\right)(\mathrm{OH})_{6} \cdot 2 \mathrm{H}_{2} \mathrm{O}$ posnjakite
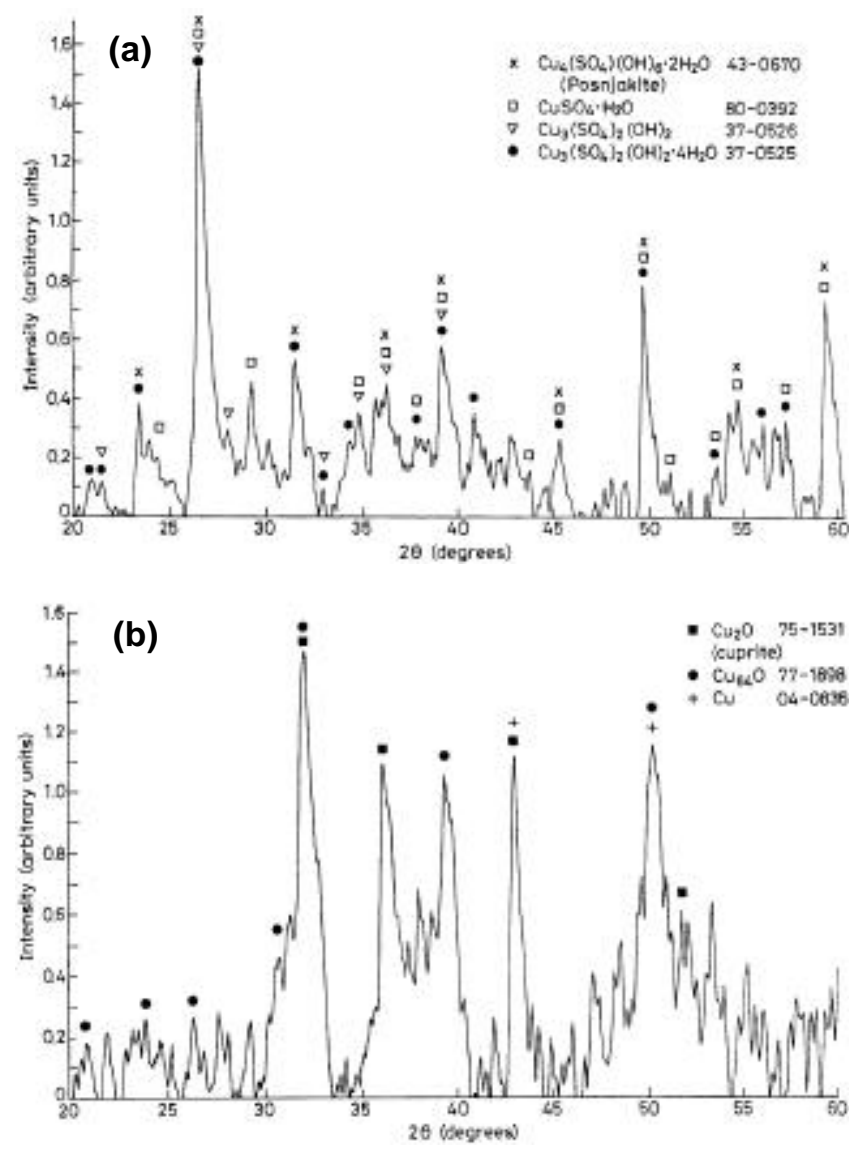

Figure 1. X-ray diffraction pattern from the surface of the chalcolithic $\mathrm{Cu}$ sample (a) before and (b) after slightly polishing the surface of the sample. The peaks corresponding to the identified phases have been marked in both the patterns.
(JCPDF 43-0670), $\mathrm{CuSO}_{4} \cdot \mathrm{H}_{2} \mathrm{O}$ (JCPDF 80-0392), $\mathrm{Cu}_{3}$ $\left(\mathrm{SO}_{4}\right)_{2}(\mathrm{OH})_{2}(\mathrm{JCPDF} 37-0526)$ and $\mathrm{Cu}_{3}\left(\mathrm{SO}_{4}\right)_{2}(\mathrm{OH})_{2} \cdot 4 \mathrm{H}_{2} \mathrm{O}$ (JCPDF 37-0525).

The XRD patterns were re-determined after a slight polishing procedure using emery paper. The XRD patterns from all the surfaces were again similar. A typical pattern after slight polishing procedure is shown in figure $1 \mathrm{~b}$. Analysis of these XRD patterns revealed that the phases were primarily copper oxide phases (figure $1 \mathrm{~b}$ ). The identification of peaks corresponding to $\mathrm{Cu}_{64} \mathrm{O}$ is interesting because it indicated that a suboxide, rich in $\mathrm{Cu}$, was present and this must be present below the cuprite $\left(\mathrm{Cu}_{2} \mathrm{O}\right)$ phase in the patina. The peaks from the $\mathrm{Cu}$ matrix were relatively more intense than in the earlier case (figure 1a). This indicates that the information provided by figure $1 \mathrm{~b}$ would apply to the nature of corrosion products near the metal-scale interface. The XRD patterns before polishing and after polishing of the sample surface help in understanding the sequence of formation of corrosion products. The results of the analysis agree with the known general behaviour for corrosion of copper in soil environments (Leygraf and Graedel 2000). In the corrosion of copper in soil (and also atmospheric environments), the first product to form is cuprite. In the presence of $S$ in the environment, the formation of sulfates and oxysulfates is favoured and these phases are generally found above the copper oxide-containing layer. This behaviour has also been observed in the present case of the chalcolithic copper chisel.

\subsection{Microstructural analysis}

The microstructure of the sample was analysed by optical and scanning electron microscopy (SEM). Photographs at different magnifications were obtained from different locations in the sample. Microstructural analysis revealed an almost equiaxed microstructure containing entrapped second phase inclusions in the centre of the sample (figure $2 a$ ). Some of the grains revealed annealing twins (figure b). At ambient temperatures, copper deforms by slip, while deformation by twinning is possible only at low temperatures. Moreover, deformation twins appear jagged, unlike the twins seen in figure $2 b$. Therefore, the twins noticed in figure $2 \mathrm{~b}$ are annealing twins. This provides the first indication that the object was first cast into shape. The entrapped second phase inclusions were generally spherical in shape in the centre, whereas some inclusions, especially those near the edge of the sample, were deformed. The etching in some grains was non-uniform due to coring effects, similar to that observed in an OCP $\mathrm{Cu}$ object studied earlier (Balasubramaniam et al 2002). These coring effects result during the initial casting of the object. As they were not removed in the sample, it indicates that the $\mathrm{Cu}$ chisel has been initially cast into shape. 
The microstructure was not completely homogeneous as the microstructure from near two opposite surfaces of the sample was quite different (figures $3 \mathrm{a}-\mathrm{c}$ ). The grains were more deformed compared to the grains in the interior. These microstructures reveal a cold worked structure with numerous slip bands. The important conclusion that can be deduced from these microstructures is that the initially cast chisel had been cold-worked to provide the final shaping operation to the chisel. It is also interesting to note the possible reason why the shaping operation was provided on only two opposite faces and not on all the four faces. This was because the chisel was finally hammered to the shape of a flat edge and for this purpose, deformation of only two faces was required. Therefore, based on the microstructural observations, it can be concluded that the chalcolithic $\mathrm{Cu}$ chisel was initially cast and later was cold-worked to produce the shape of the chisel.

Interestingly, there were no stress corrosion cracks emanating from the edges or corners of the sample. Some features of corrosion attack can also be observed in the microstructures obtained from the edges (figure 3 ). The microstructures (figures $3 a$ and $b$ ) from near the edge of
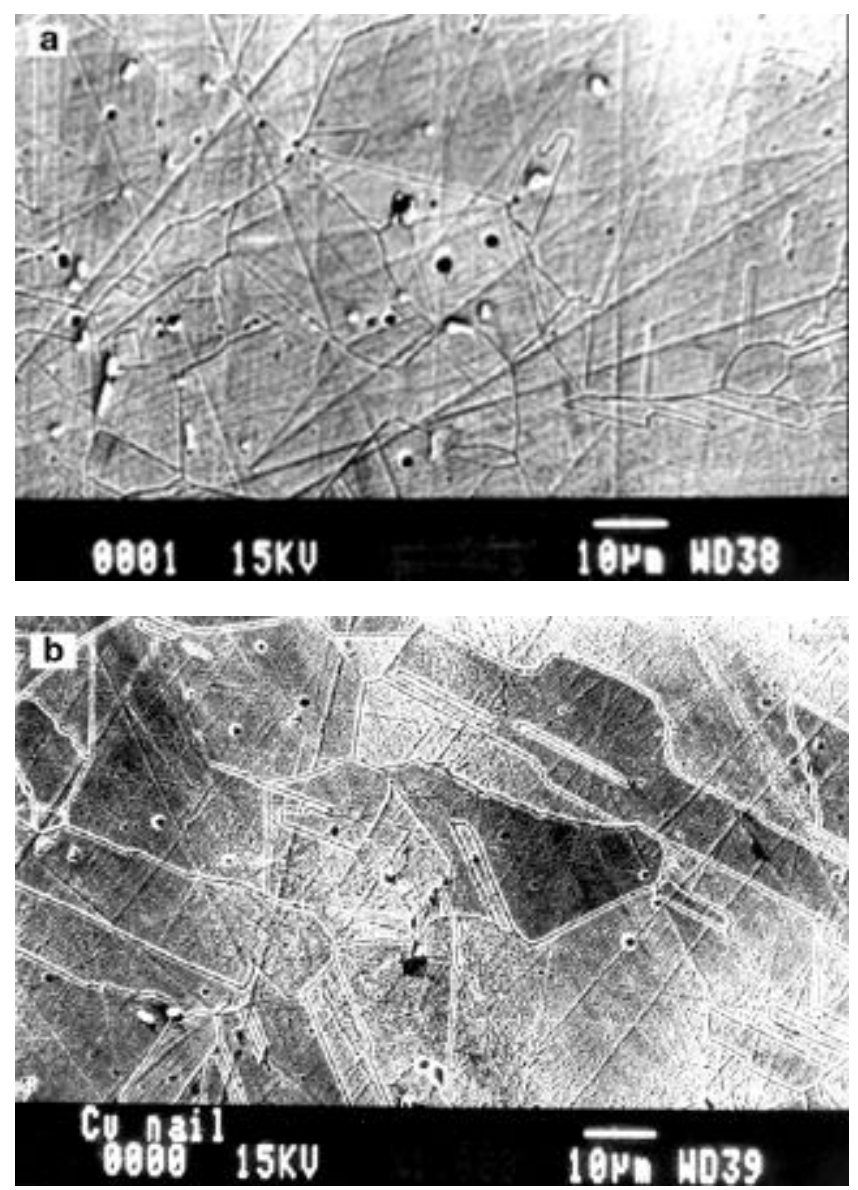

Figure 2. SEM micrographs obtained from the centre of the chisel cross-section showing entrapped second phase spherical inclusions inside the grains. Also annealing twins can be observed in some of the grains. the sample show the corrosion layer on right side of the photograph. The incursion of corrosion products into the matrix appears to occur along grain boundaries of the underlying matrix (see figures $3 \mathrm{~b}$ and $\mathrm{c}$ ). The intergranular
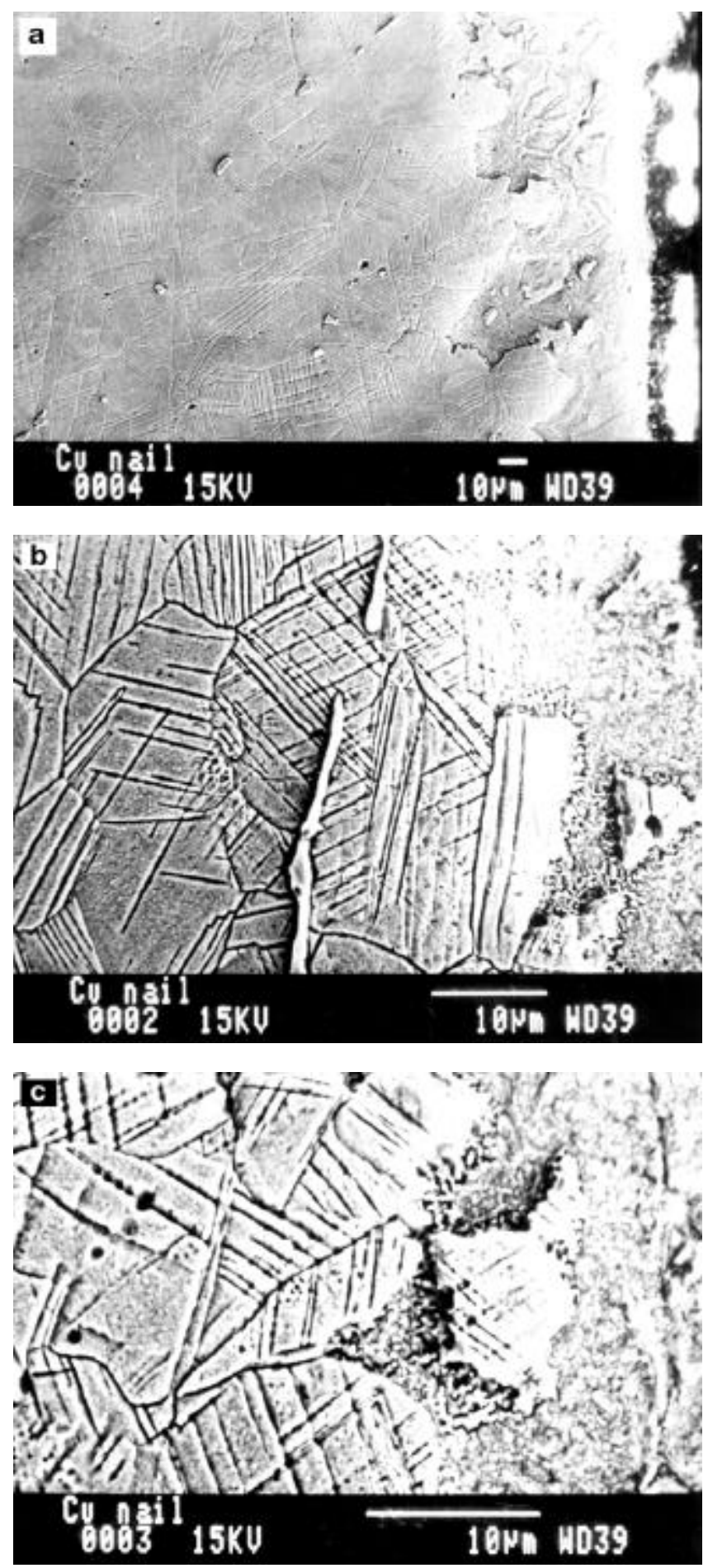

Figure 3. SEM micrographs photographed from one of the edges of the sample, showing deformed grains and incursion of corrosion products along grain boundaries. Corrosion layer is on right side of the photograph. Elongated bright inclusion can also be seen in $\mathbf{b}$. 
nature of corrosion attack is understandable because of the higher-energy state of material at these locations. Nevertheless, it is also important to note that the incursion of corrosion products along the grain boundaries was not deep enough to warrant the use of the term pitting to describe this kind of environmental corrosion. A complementary conclusion is the lack of any environmentally induced cracking in this material. This is understandable because dangerous chloride ions were not present in the soil environment to which the chisel was exposed. This conclusion is based on absence of chlorides in the surface patina (figures $1 \mathrm{a}$ and $\mathrm{b}$ ). Therefore, in the environments where chloride ions are excluded, as in the present study, microstructural investigations on archaeological copper provide evidence that there is no danger of stress corrosion cracking. This observation has important implications in the selection of $\mathrm{Cu}$ as a material for long-term nuclear storage canisters.

Microstructural analysis of the chalcolithic $\mathrm{Cu}$ also revealed second phase inclusions (figure 2), which appeared dark in the optical micrograph. In case of pure modern $\mathrm{Cu}$, second phase inclusions were not observed. The entrapped inclusions were elongated near the edges of the sample, indicating that the slag particles were amenable to deformation at room temperature without cracking (figure 3b). It is important to note that deformation was noticed only on two sides of the sample, thereby suggesting the possible mode of manufacture of the copper chisel. The elongated slag inclusions were parallel to the surface and such inclusions were not observed inside the sample. The entrapped inclusions in the middle of the sample were spherical (figure $2 b$ ).

The entrapped inclusions and the matrix were analysed qualitatively for their compositions in the SEM. The analysis was performed in the region shown in figure 4 . The spectrum obtained from a region in the matrix is provided in figure 5. The composition of the matrix was essentially pure $\mathrm{Cu}$, with trace amounts of As and $\mathrm{Sn}$. The spectrum from the bright inclusions (one of them has been marked as 1 ) in figure 4 is shown in figure 6 , confirming it to be pure $\mathrm{Pb}$. The spectrum from the dark particles seen in figure 4 is presented in figure 7 , from which it is concluded that these inclusions are essentially $\mathrm{Cu}$ sulfide (major) and Fe sulfide (minor). The second phase inclusions in an OCP $\mathrm{Cu}$ were earlier analysed in an electron probe microanalyser as sulfide of $\mathrm{Cu}$ (Balasubramaniam et al 2002). This seems to indicate that the technology for copper extraction and application remained almost similar for a large period in Indian history based on the analysis of the chalcolithic (2350-1800 BC) and OCP (2650-800 BC) coppers.

The volume fraction of second phase inclusions and grain size was determined as per the procedure discussed earlier. The image analysis results are given in table 1 . The volume fraction of inclusions was relatively low and almost similar to that of OCP $\mathrm{Cu}$ analysed earlier (Laha et al 2002), thereby suggesting similarities between the OCP and chalcolithic coppers. The grain size of chalcolithic $\mathrm{Cu}$ was slightly lower compared to modern $\mathrm{Cu}$ or OCP $\mathrm{Cu}$, suggesting that the $\mathrm{Cu}$ chisel was subjected to

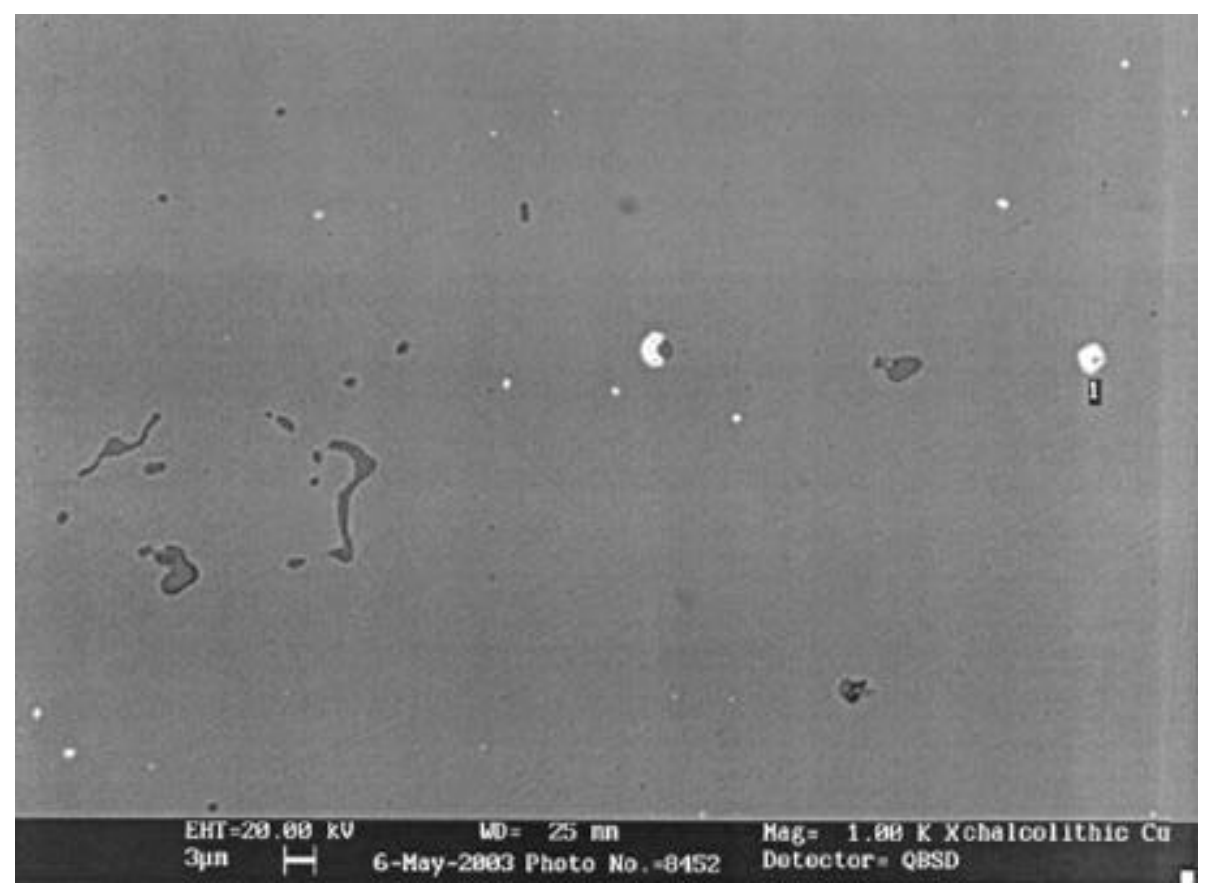

Figure 4. SEM back scattered electron micrograph showing the region that was analysed qualitatively for compositions. 
deformation by hammering action, which was also confirmed by microstructural analysis.

\subsection{Microhardness}

The variation of microhardness as a function of distance into the material from the surface is shown in figure 8 . The hardness profiles were almost constant on two opposite faces, while on the other two faces, the hardness was much higher near the surface, which progressively decreased on moving towards the interior (figure 8). The hardness of the matrix in the centre was almost similar in all profiles. The microhardness measurements confirmed deformation on two opposite surfaces. On the other two surfaces, there was no significant variation in the hardness from surface to the middle of the specimen.

\subsection{Electrochemical characterization}

Electrochemical behaviour provides valuable information about corrosion resistance. Copper canisters have been proposed for long-term storage of nuclear wastes deep inside the ground (Rosborg et al 2003). It is, therefore, important to know if $\mathrm{Cu}$ would be resistant to corrosion over a very long period of time, because the long-lived nuclear wastes have to be stored for more than 10000 years (Rosborg et al 2003). It is in this context that archaeological analogues can provide valuable information regarding the expected behaviour of copper canisters for long-term nuclear waste storage. The copper sample used in the study was a very old sample, of conservative age 3800 years. From microstructural analysis it was

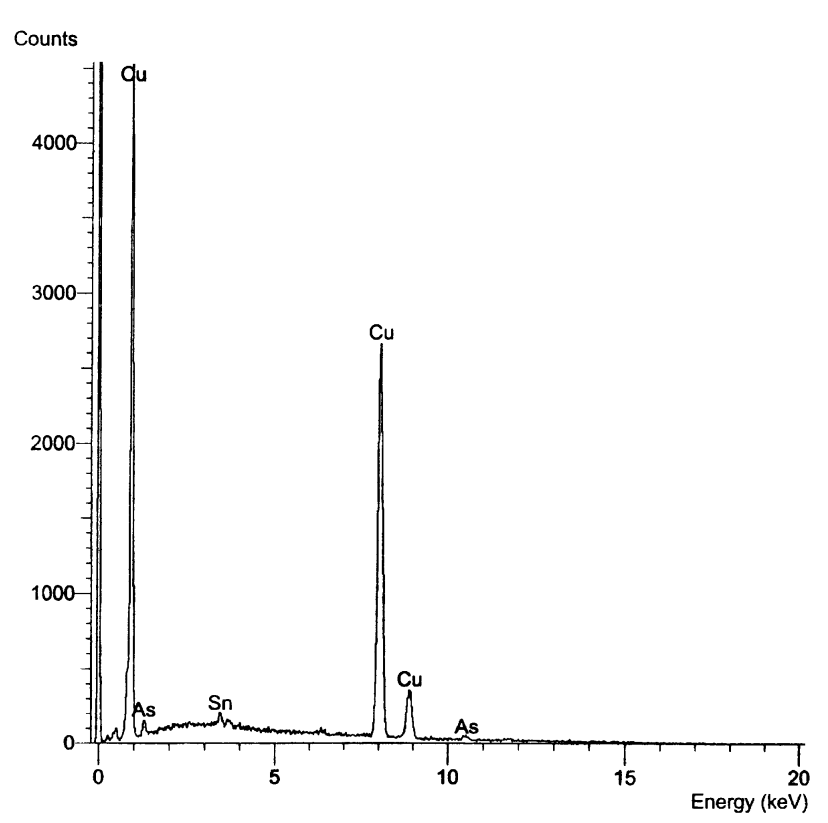

Figure 5. The spectrum obtained from a region in the matrix in figure 4 , indicating that composition of the matrix is essentially pure $\mathrm{Cu}$, with trace amounts of $\mathrm{As}$ and $\mathrm{Sn}$. found that the degree of corrosion was not severe and moreover, stress corrosion cracking was not evident from the surfaces of the sample. Electrochemical characterization revealed information about its corrosion properties, which can be compared with that of modern $\mathrm{Cu}$.

The free corrosion potential of the chalcolithic copper sample stabilized relatively quickly on immersion in the electrolyte. This indicates that equilibrium corrosion con-

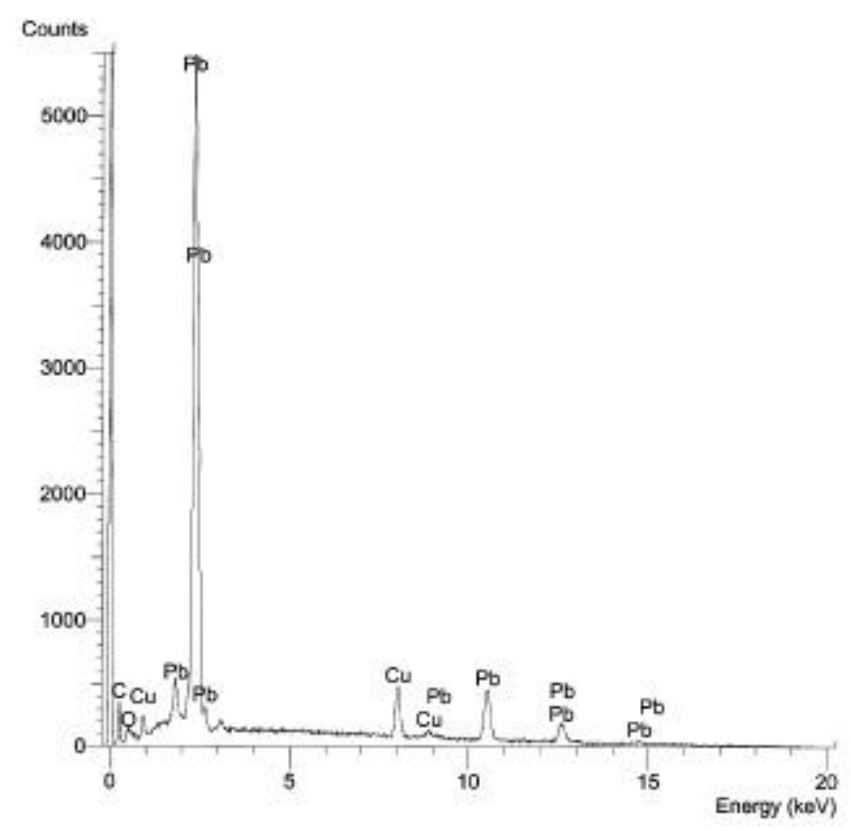

Figure 6. The spectrum from the bright inclusions (one of them has been marked as 1) in figure 4 , confirming it to be pure $\mathrm{Pb}$.

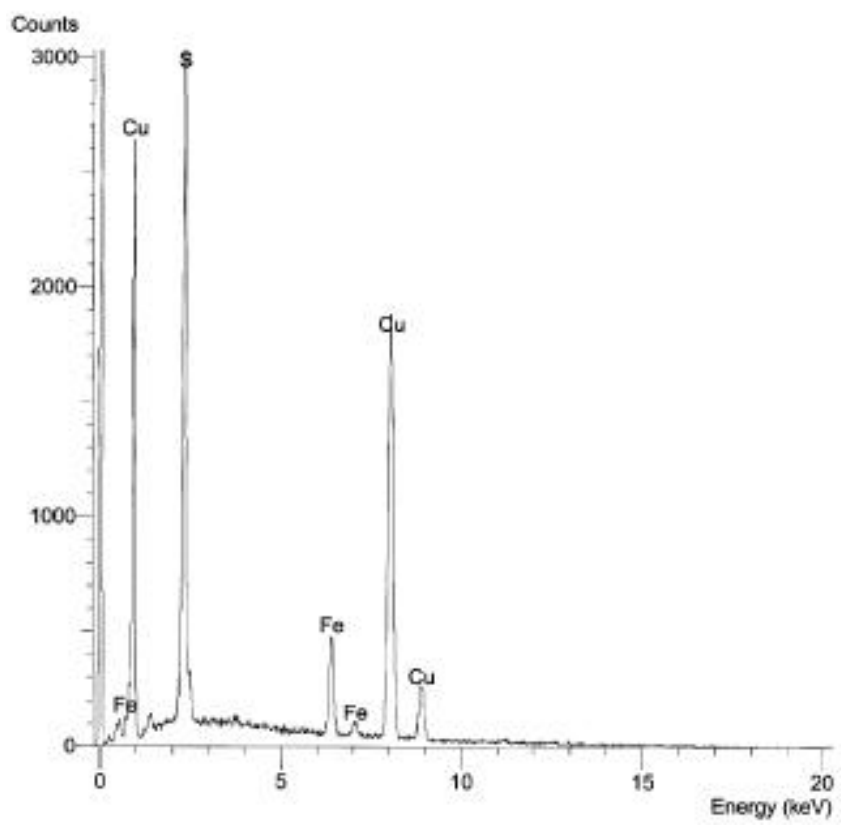

Figure 7. The spectrum from the dark particles seen in figure 4, confirming that these inclusions are essentially $\mathrm{Cu}$ sulfide (major) and Fe sulfide (minor). 
ditions (i.e. supporting anodic and cathodic reactions) are established fairly quickly on the surface of this sample. This behaviour was similar to that observed for modern $\mathrm{Cu}$. Therefore, the entrapped slag inclusions in chalcolithic $\mathrm{Cu}$ do not deleteriously affect the establishment of equilibrium corrosion conditions on the surface, which is understandable as the volume fraction of entrapped inclusions was relatively low (table 1). The potentiodynamic polarization curves for modern and chalcolithic $\mathrm{Cu}$ samples in $3.5 \mathrm{wt} \% \mathrm{NaCl}$ solution are shown in figure 9. Both the copper samples exhibited similar electrochemical behaviour in the $\mathrm{NaCl}$ solution. The polarization behaviour of modern $\mathrm{Cu}$ was in excellent agreement with published data (Trethewey and Chamberlain 1988). The surface film that formed at anodic potentials was very stable because no pitting was observed even up to $+1400 \mathrm{mV}$ vs SCE. A thin adherent surface film was visually observable in both the samples even after removal from the solution, at the end of each experiment. The various potentials like zero current potential, primary passivation potential, etc were similar for the samples indicating that the entrapped slag inclusions did not significantly affect polarization behaviour.

The major difference between the two samples was the presence of second phase inclusions in the case of the chalcolithic $\mathrm{Cu}$ sample. It was anticipated that the presence of second phase inclusions would affect the corrosion rates. Table 2 presents the results of Tafel extrapolation method for modern, chalcolithic and OCP coppers. The anodic and cathodic Tafel slopes were almost similar for the three samples, which is reasonable. The corrosion rate of chalcolithic $\mathrm{Cu}$ sample $(175 \mu \mathrm{m} / \mathrm{y})$ was higher than modern $\mathrm{Cu}(55 \mu \mathrm{m} / \mathrm{y})$. The corrosion rate for modern $\mathrm{Cu}$ agreed well with the published corrosion rate for $\mathrm{Cu}$ in seawater $(25-127 \mu \mathrm{m} / \mathrm{y})$ (LaQue 1975). The second phase slag particles appear to have slightly enhanced the dissolution tendencies, which could probably be due to galvanic coupling action of the $\mathrm{Cu}$ matrix with the slag inclusions. It is to be noted that the sulfides are electrically conducting and they aid in the establishment of local galvanic cells (Wranglen 1969). The effect of the inclusions was not significant because the volume fraction of inclusions was relatively low and, moreover, they were not interconnected but widely dispersed (figure 2). In order to double-check the calculated corrosion rate from the Tafel extrapolation technique, the corrosion rate of chalcolithic copper was also determined using the linear polarization technique. The corrosion rate was an order of magnitude lower, possibly due to the presence of unreduced surface film on the surface of the sample compared to the Tafel experiment where the specimen was polarized to a larger cathodic over potential.

Table 1. Volume fraction of inclusions and grain size, calculated by image analysis.

\begin{tabular}{lccccccc}
\hline & \multicolumn{3}{c}{ Volume fraction } & & \multicolumn{3}{c}{ Grain size } \\
\cline { 2 - 4 } \cline { 6 - 8 } $\begin{array}{l}\text { Copper } \\
\text { sample }\end{array}$ & $\% V_{\mathrm{v}}$ & Std. dev. & $\%$ error $( \pm)$ & & Size $(\mu \mathrm{m})$ & Std. dev. & $\%$ error $( \pm)$ \\
\hline Modern & - & - & - & & 19.47 & 1.57 & 2.95 \\
Chalcolithic & 2.78 & 0.59 & 7.68 & & 14.10 & 2.66 & 6.88 \\
OCP & 2.11 & 0.90 & 11.02 & & 19.50 & 3.79 & 7.09 \\
\hline
\end{tabular}

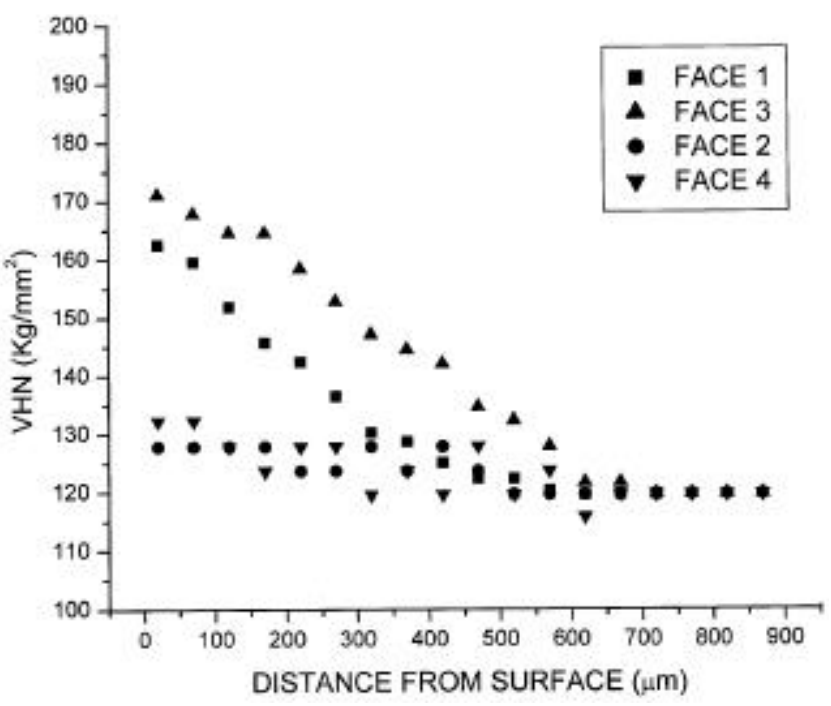

Figure 8. Variation of microhardness as a function of distance into the surface from all the four surfaces.

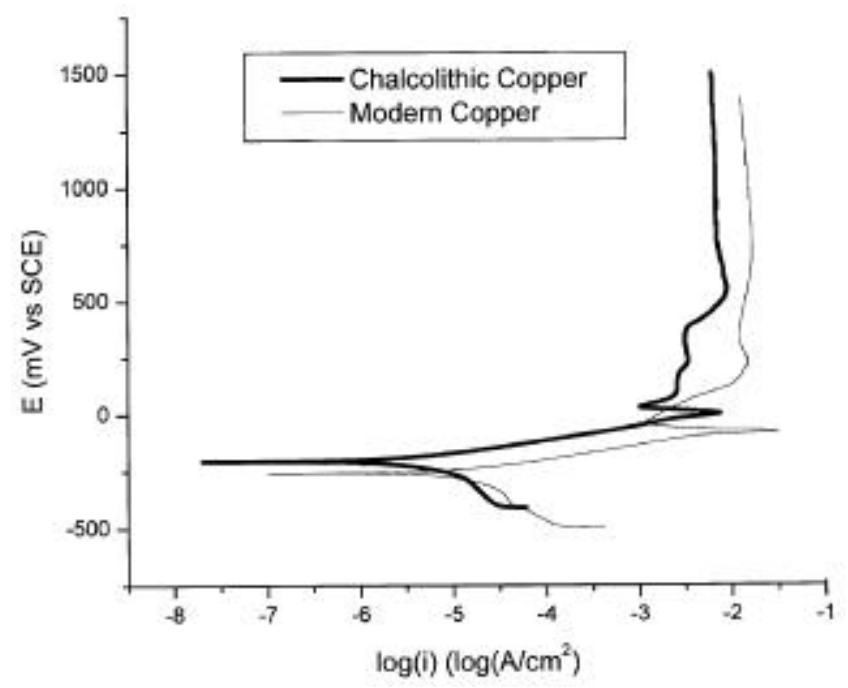

Figure 9. Potentiodynamic polarization curves for modern and chalcolithic coppers in aerated $3.5 \mathrm{wt} \% \mathrm{NaCl}$ solution. 
Table 2. Results of Tafel extrapolation experiments.

\begin{tabular}{lccccc}
\hline $\begin{array}{l}\text { Copper } \\
\text { specimen }\end{array}$ & $\begin{array}{c}\beta_{\mathrm{c}} \\
(\mathrm{mV} / \mathrm{dec})\end{array}$ & $\begin{array}{c}\beta_{\mathrm{a}} \\
(\mathrm{mV} / \mathrm{dec})\end{array}$ & $\begin{array}{c}i_{\text {corr }} \\
\left(\mu \mathrm{A} / \mathrm{cm}^{2}\right)\end{array}$ & $\begin{array}{c}\text { Corrosion rate } \\
(\mu \mathrm{m} / \mathrm{y})\end{array}$ & $\begin{array}{c}\text { Zero current potential } \\
(\mathrm{mV} \text { vs SCE })\end{array}$ \\
\hline Modern & -26 & 21 & 0.49 & 55 & -226 \\
Chalcolithic & -32 & 37 & 0.63 & 175 & -172 \\
OCP & -28 & 37 & 0.67 & 185 & -194 \\
\hline
\end{tabular}

\section{Conclusions}

The microstructure of the material of construction of a chalcolithic (2350-1800 BC) copper chisel from Balathal has been characterized by stereological methods. The smaller grain size, deformed grains and deformed inclusions near the surfaces and variation in the microhardness of the sample at different points suggests that the copper chisel was processed by cold deformation after casting of the square cross-section chisel. The electrochemical behaviour of chalcolithic $\mathrm{Cu}$ has been characterized and compared with that of a modern $\mathrm{Cu}$ sample by potentiodynamic polarization studies. The corrosion rate, determined by Tafel extrapolation technique in $3.5 \% \mathrm{NaCl}$ solution, of chalcolithic $\mathrm{Cu}$ was only marginally higher than that of modern $\mathrm{Cu}$. The higher rate of corrosion in case of archaeological $\mathrm{Cu}$ has been attributed to the presence of second phase sulfide inclusions.

\section{Acknowledgements}

The authors would like to thank Prof. V N Misra and the Archaeological Museum, Deccan College, Pune, for providing the chalcolithic copper chisel sample used in the present study. (RB) would like to acknowledge the equipment grant (potentiostat) from the Alexander von Humboldt foundation. The authors also acknowledge the kind assistance of Dr V Joshi, DMRL, Hyderabad, in qualitative compositional analysis.

\section{References}

ASTM 1987 Metals test methods and analytical procedures, Annual Book of ASTM Standards, Volume 3.02, Section 3, Philadelphia, USA

Balasubramaniam R, Mungole M N, Prabhakar V N, Sharma D V and Banerjee D 2002 Man and Environment 3689

JCPDF 2001 Powder Diffraction Files, PCPDFWIN Software, Joint Committee on Powder Diffraction StandardsInternational Centre for Diffraction Data, Swarthmore, USA

Laha T, Shankar J, Balasubramaniam R, Tewari A, Prabhakar V N, Sharma D V and Banerjee D 2002 Indian Journal of History of Science 37320

LaQue F L 1975 Marine corrosion-causes and prevention (New York: John Wiley) p. 146

Leygraf C and Graedel T 2000 Atmospheric corrosion (New York: Wiley-Interscience) pp 140-148

Misra V N, Shinde V, Mohanty R K, Dalal K, Mishra A, Pandey L and Kharakwal J 1995 Man and Environment 20 57

Misra V N, Shinde V, Mohanty R K, Pandey L and Kharakwal J 1997 Man and Environment 3235

Rosborg B, Karnland O, Quirk G and Werme L 2003 in Proceedings of the international workshop on prediction of long term corrosion behaviour in nuclear waste systems (Cadarache, France: European Federation of Corrosion) pp 412 423

Trethewey K R and Chamberlain J 1988 Corrosion for students of science and engineering (Harlow: Longman Scientific) p. 92

Wranglen G 1969 Corros. Sci. 9585 